\title{
Políticas indígenas e indigenistas no Continente de São Pedro na segunda metade do século XVIII
}

\author{
Indigenous and indigenista policies on the Continent of São Pedro in the second half of the 18th \\ century
}

\author{
Karina Moreira Ribeiro da Silva e Melo \\ https://orcid.org/0000-0002-0613-6764 \\ Universidade de Pernambuco
}

\begin{abstract}
Resumo: O objetivo deste artigo é analisar as maneiras através das quais as políticas indigenistas foram vistas e praticadas por sujeitos históricos relacionados à formação e manutenção dos aldeamentos indígenas de Nossa Senhora dos Anjos e São Nicolau do Rio Pardo na segunda metade do século XVIII. Os indígenas, as autoridades coloniais e a sociedade envolvente estabeleceram conflitos e alianças em torno das diretrizes assimilacionistas oriundas do Diretório dos Índios e do contexto de estabelecimento de fronteiras na região platina. A documentação de cunho administrativo analisada é proveniente do Arquivo Histórico do Rio Grande do Sul, do Arquivo Nacional do Rio de Janeiro, da Biblioteca Nacional de Lisboa e da Biblioteca Nacional do Rio de Janeiro. Houve estratégias e tomadas de posição políticas distintas para promover a integração social, algumas delas incluindo violência, tanto por parte dos indígenas aldeados em São Nicolau do Rio Pardo e Nossa Senhora dos Anjos, quanto por parte de autoridades coloniais e particulares. As possibilidades de escolha não foram equânimes, mas algumas delas, feitas em situações limite, foram importantes nos processos de apropriação cultural e, por conseguinte, nos processos de formação social e reelaboração de identidades no Continente.
\end{abstract}

Palavras-chave: Políticas indígenas. Políticas indigenistas. Aldeamentos no Continente de São Pedro.

\begin{abstract}
The purpose of this article is to analyse the ways in wich indigenous policies were seen and praticed by historical subjects related to the formation and maintenance of two indigenous villages in the second half of the 18th century. The indigenous people, the colonial authorities and the surrounding society have established conflicts and alliances around the assimilationist guidelines from the Directory of Indians and the context of establishing borders in the platinum region. The administrative documentation analyzed comes from the Historical Archive of Rio Grande do Sul, the National Archive of Rio de Janeiro, the National Library of Lisbon and the National Library of Rio de Janeiro. There were different strategies and political positions taken to promote social integration, some of them including violence, both by the indigenous people living in São Nicolau do Rio Pardo and Nossa Senhora dos Anjos, and by colonial and private authorities. The choice possibilities were not equitable, but some of them, made in extreme situations, were important in the processes of cultural appropriation and, therefore, in the processes of social formation and reworking of identities in the Continent.
\end{abstract}

Keywords: Indigenous policies. Indigenist policies. villages on the Continent of São Pedro.

\section{Introdução}

Em meados do século XVIII, as disputas territoriais entre Portugal e Espanha se intensificaram. As Coroas ibéricas buscaram estabelecer suas possessões territoriais na região do rio da Prata através do Tratado de Madri (1750). Em virtude das contestações indígenas e dos conflitos desencadeados pela Guerra Guaranítica, o Tratado de Madri foi anulado pelo Tratado El Pardo, em 1761. Os portugueses ficaram receosos de uma possível união entre os espanhóis e os 
indígenas das dezenas de povoados missioneiros espalhados pelos limites platinos. Estabeleceram negociações com os indígenas, que se negaram a simplesmente deixar seus povos em virtude de tratados e acordos estabelecidos pelos governos coloniais. Destas negociações resultaram a migração de parte dos povos das Missões Jesuíticas Ocidentais, sob domínio espanhol, para o Continente do Rio Grande de São Pedro, dando origem à formação de cinco aldeamentos entre 1751 e 1762. Os indígenas instalaram-se inicialmente nos arredores do quartel de Rio Pardo e depois nos campos de Viamão, formando os aldeamentos de São Nicolau do Rio Pardo (1757), Nossa Senhora dos Anjos (1763) - atual Gravataí, Nossa Senhora da Conceição do Estreito da Cachoeira (1753), Santo Antônio da Patrulha (1758) e Nossa Senhora do Rio Pardo do Jacuí, cujas datas de fundação e extinção não se sabe ao certo (LANGER, 2005, p. 128). São Nicolau do Rio Pardo foi o aldeamento mais duradouro da história do Continente do Rio Grande e Nossa Senhora dos Anjos o maior, onde teriam se estabelecido aproximadamente três mil pessoas ${ }^{1}$ (KÜHN, 2007, p. 1). Estes dois primeiros aldeamentos foram mais duradouros e mais povoados. Por tais motivos, entre outros, foram também mais documentados e explorados pela historiografia. A documentação sobre os três últimos, ao contrário, é mais escassa. Assim, manteremos o foco nos aldeamentos de Nossa Senhora dos Anjos e São Nicolau do Rio Pardo para tratar de aspectos das políticas indígenas e indigenistas no Continente. Dos cinco aldeamentos guarani-missioneiros fundados em território luso por ocasião de vários fluxos migratórios, São Nicolau do Rio Pardo parecia ser o ponto de partida e chegada para os demais. Dele foram transferidas as populações indígenas que formaram os aldeamentos de Santo Antônio da Patrulha e de Nossa Senhora dos Anjos; assim como também recebeu os indígenas dos aldeamentos que se mantiveram por pouco tempo, como o de Nossa Senhora da Conceição do Estreito e provavelmente São Nicolau do Rio Pardo do Jacuí. São Nicolau do Rio Pardo foi o primeiro aldeamento de origem guarani-missioneira do Continente constituído nos moldes que remetem aos da política assimilacionista do marquês de Pombal e o último a se desmantelar. Dizer que o aldeamento foi constituído nos moldes da política pombalina não significa afirmar que foi criado ancorado nela. Dificilmente, consegue-se praticar uma legislação tão logo ela seja implantada. Em contrapartida, ela pode continuar a vigorar mesmo após sua extinção.

As relações entre os indígenas e a sociedade que se formava mostraram-se repletas de dinâmicas e estratégias distintas por parte das Coroas ibéricas, dos colonos da região e dos próprios indígenas missioneiros. Tais relações não podem ser entendidas sem que nos remetamos ao caráter assimilacionista da legislação pombalina. ${ }^{2} \mathrm{~A}$ assimilação dos indígenas ao modus vivendi da sociedade envolvente previa a adoção de elementos europeus e a eliminação de traços e valores culturais característicos. Analisar as medidas administrativas tomadas pela Coroa portuguesa a partir do Diretório dos Índios (1757-1758), em relação aos indígenas dos aldeamentos do Continente, permite compreender melhor como a política pombalina foi arquitetada, recebida e posta em exercício na segunda metade do século XVIII. Através do exame de fontes primárias de caráter legislativo e administrativo do período em questão, como instruções, portarias, "bandos" ${ }^{3}$ e cartas, é possível abordar aspectos sobre a política pombalina no Continente e os modos indígenas de fazer política e lidar com as diretrizes assimilacionistas.

\footnotetext{
${ }^{1}$ Esse dado torna-se importante para pensar o impacto dessa população indígena no âmbito das relações socioculturais que se estabeleciam. Se comparada à população de Viamão, a aldeia dos Anjos tinha o dobro de habitantes, contando com portugueses, cativos africanos e indígenas.

2 Sebastião de Carvalho e Melo, o Marquês de Pombal, foi o ministro todo-poderoso de D. José I (1750-1777) e principal mentor da política indigenista, que ocupava lugar de destaque no bojo das reformas político-administrativas, a fim de recuperar a defasada economia portuguesa.

${ }^{3}$ Expressão de época usada para designar anúncio público de ordem ou decreto.
} 


\section{Aldeamentos no Continente sob a ótica indigenista}

As relações entre portugueses e indígenas foram em grande parte regidas por um conjunto de normas e instruções, o Diretório dos Índios. O principal objetivo do Diretório era inserir os indígenas às sociedades que se formavam na América portuguesa, e a sua principal característica era o assimilacionismo. A política de assimilação dos indígenas previa a eliminação de quaisquer diferenças entre brancos e indígenas. A integração dos segundos só seria possível se eles fossem "civilizados" de acordo com os hábitos, costumes religiosos e culturais dos portugueses. Tratava-se principalmente de que os índios "esquecessem" os valores e traços culturais indígenas, mas também de invalidar a experiência pela qual haviam passado com os jesuítas nas missões. Enquanto os jesuítas haviam dado maior importância à educação religiosa como método para "civilizar" os índios, a legislação do Diretório tratava da administração dos indígenas valorizando tanto aspectos religiosos, quanto econômicos, políticos e culturais no processo de "civilização".

A política indigenista do Marquês de Pombal foi organizada de acordo com as novas pautas coloniais da segunda metade do Setecentos. Além do contexto local, como vimos, a política exposta no Diretório dos Índios influiu na formação dos aldeamentos guarani-missioneiros. Francisco Xavier de Mendonça Furtado, irmão do Marquês de Pombal, elaborou o Diretório em decorrência de suas atividades nas demarcações territoriais do Tratado de Madri. ${ }^{4}$ Referindo-se "aos índios que se acham em Viamão", Mendonça Furtado, que era governador e Capitão-General do estado do GrãoPará e Maranhão, considerava que "essa miserável gente" havia sido deixada "na mesma desordem e brutalidade em que foram criados pelos jesuítas, sem que se cuidasse na sua civilização, na criação dos filhos; e o que é mais, até sem conhecimentos dos principais dogmas da religião católica romana". (REVISTA TRIMENSAL DO IHGB, 1872, p. 215).

O Diretório teve suas raízes em um projeto de povoamento do Brasil, que previa a ocupação e o povoamento de territórios com a finalidade de garantir a posse da terra. Pensado inicialmente para o Estado do Grão-Pará e Maranhão, teve seu raio de ação ampliado para outras regiões do Brasil e reorganizou populações indígenas procurando eliminar definitivamente as diferenças através dos aldeamentos, um traço primordial da política indigenista. Dentre as principais medidas assimilacionistas presentes no Diretório, pode-se mencionar o estímulo aos casamentos mistos, o incentivo ao trabalho agrícola, ao aprendizado de artes e ofícios mecânicos, e a eliminação da língua e das práticas religiosas indígenas. Fica claro que a igualdade entre indígenas e portugueses dependia do sucesso em extirpar características culturais dos indígenas, de modo que estes se integrassem ao modo de vida daqueles e não o oposto. A igualdade, que garantia aos indígenas aldeados a mesma condição dos portugueses, era uma outra proposta para regular a transição entre a condição de "gentios" e "selvagens" para a condição de vassalos do rei. No decorrer da segunda metade do século XVIII, a hierarquia entre os vassalos foi "potencializada pelo Diretório" através do acesso facilitado de agentes do governo e militares ao trabalho compulsório dos indígenas (SAMPAIO, 2011, p. 32).

Conforme Beatriz Perrone-Moisés, divididos entre aliados e hostis, os povos indígenas receberam tratamento diferenciado dos poderes coloniais (PERRONE-MOISÉS, 1992). Os povos aldeados eram considerados aliados e normalmente concentravam-se próximos às vilas nascentes, prestando-se como proteção contra os povos "hostis" e como estoque de mão-de-obra para os trabalhos da economia colonial. Dessa maneira, os aldeados eram considerados "vassalos úteis", enquanto os povos hostis, sob a ótica indigenista, eram justamente aqueles que permaneciam fora de controle, constituindo-se em ameaça. Logo, o aldeamento era a concretização de uma forma de controle territorial e social sobre os nativos e este controle requereu a definição do trato da terra (a

\footnotetext{
${ }^{4}$ O Diretório foi assinado em 1757 por Francisco Xavier de Mendonça Furtado e aprovado em 1758 pelo Marquês de Pombal.

${ }^{5}$ Francisco Xavier de Mendonça Furtado era irmão do Marquês de Pombal e comissário para demarcação do Tratado de Madri na região amazônica.
} 
dita aldeia), na qual estariam contidos e assentados, liberando assim o restante do espaço para a expansão e a ocupação colonial. O aldeamento "garante a conversão, a ocupação do território, sua defesa e uma constante reserva de mão-de-obra para o desenvolvimento da colônia" (PERRONEMOISÉS, 1992, p. 120). A questão indígena esteve, portanto, indissociavelmente ligada aos assuntos de Estado e segundo Rita Heloísa de Almeida, a história da legislação indígena no período colonial "[...] pode ser escrita ou lida no contexto das relações de trabalho. Isto porque todas as leis gravitam em torno da questão sobre quem exerce o controle e a administração dos índios, no que de fundamental riqueza representaram durante a colonização, ou seja, como população e força de trabalho (ALMEIDA, 1997, p. 36-37)". ${ }^{\circ}$

O uso da mão-de-obra indígena, tanto por parte de particulares quanto por parte do governo, foi um dos maiores problemas da administração portuguesa no Continente. As condições de circulação do indígena e a regulamentação do uso da sua mão-de-obra eram fontes de preocupações constantes na documentação estudada. Havia diversos interesses em jogo, sobretudo os de uma facção da elite local que se beneficiava do trabalho dos indígenas aldeados em Nossa Senhora dos Anjos, por exemplo. Percebe-se que o uso da mão-de-obra indígena se dava de maneiras não muito padronizadas. No governo de José Custódio de Sá e Faria (17641769) era comum que os particulares decidissem sobre o quanto pagariam pela prestação de serviços dos indígenas, ou que simplesmente, não pagassem. Também não era raro que os indígenas sofressem maus tratos ${ }^{7}$ e fossem mantidos sob a guarda de particulares, apesar de estarem com a licença para sair do aldeamento vencida.

No governo de José Custódio parece não ter havido interesse em controlar o aluguel do serviço dos índios. Segundo ele, os índios continuavam "dispersos por toda província, ou já vagando sem destino certo, ou alugados por alguns moradores, que menos atentos à consciência lhe deixam de pagar o trabalho" (ANRJ, Cód. 104 v. 06, p.162, 162v.). Apesar de o governador saber que alguns particulares se aproveitavam do uso da mão-de-obra indígena, não implantou medidas para que, de fato, houvesse controle sobre a prestação de serviços. José Custódio ordenava apenas, que os indígenas fossem reconduzidos à aldeia: "[...] ordeno que dentro de um mês [...], sejam reconduzidos à Aldeia de Nossa Senhora dos Anjos todos os que se achavam ocupados em outras estâncias [...], e em quaisquer outros empregos, os quais serão obrigados a remeter à dita Aldeia as pessoas que os tiverem em seu poder" (ANRJ, Cód. 104 v. 06, p.162, 162v.).

Nesse sentido, a documentação analisada permite entrever que essa política de controle da população indígena variou de governo para governo. As informações apontam para o fato de que essa variação dependia de conchavos políticos e econômicos entre os administradores do governo português e as elites locais. Assim, o primeiro governo da década de 1770 tentava regulamentar o "aluguel" da mão-de-obra indígena, no que diz respeito ao preço e ao tempo de uso: "De um mês até um ano poderão alugar os ditos índios e índias cada mês, por um índio para carreta, roçar, ou pião, $3 \$ 000$ r. Por rapaz cada mês $1 \$ 500$ r. Por um índio domador por mês $3 \$ 600$ por algum índio oficial de carpinteiro o que merecer. Por uma índia para servir por mês $1 \$ 800$ r. Por uma índia para ama de leite por mês 3\$000". (ANRJ, Cód. 104 v. 06, p.162, 162v.)

No primeiro governo de José Marcelino, os preços foram fixados e ficou proibido conservar

\footnotetext{
${ }^{6}$ O Diretório regulava basicamente cinco aspectos a serem administrados no aldeamento. Exponho de maneira sucinta a ordem de prioridade destes aspectos, conforme classificação de Rita Heloísa de Almeida: a questão da civilização dos índios, assuntos relativos à economia, à tributação, ao comércio e à distribuição da força de trabalho indígena. No Diretório, 16 artigos são referentes à civilização; 8 à economia; 8 à fiscalização e tributação; 23 ao comércio; 14 à distribuição da força de trabalho do índio. Um número maior de artigos se destina à causa comercial (23), mesmo sem levarmos em consideração que igualmente mercantis são aqueles outros 30 artigos que tratam da economia, da fiscalização e tributação, e por fim da distribuição da mão-de-obra indígena. Apesar da divisão teórica, todos estes aspectos estão imbricados e se inserem num âmbito maior e mais complexo, o das relações e transformações socioculturais.

7 "Recomendará o dito capitão a quem alugar os índios, os tratarem com humanidade, por que hão de ser castigados, os que os tratarem como escravos, com açoites, ou castigos semelhantes. Tanto o capitão comandante como moradores me representarão as faltas, que houver a respeito do que determino para lhe dar a providência que me parecer justa". Viamão, a 22 de dezembro de 1769. Figueiredo. in SANTOS, 1990, Anexo.
} 
índios e índias, em casas e fazendas, sem a licença por escrito do comandante da aldeia. Isso não quer dizer, necessariamente, que José Marcelino tenha sido um entusiasta da política pombalina de assimilação, e que, portanto, tenha se empenhado em aplicar o Diretório dos Índios de forma mais estrita. Ao que parece, ele tentou, sem muito êxito, fazer cumprir as determinações do Diretório, aliando-as às demandas administrativas e particulares do Continente em relação aos indígenas. Sob a ótica dos portugueses, o sustento dos indígenas era uma grande despesa para a Fazenda Real. Para aliviar os gastos feitos com os indígenas, estes deveriam trabalhar, gerando uma receita que garantisse a manutenção do aldeamento. A mão-de-obra indígena ainda deveria ser útil aos moradores do Continente. O Diretório previa a utilização do serviço indígena por particulares; proibia, por outro lado, que essa utilização se desse sem método algum. Para que o trabalho indígena também trouxesse retorno financeiro ao aldeamento, era preciso que o pagamento pelo uso da mão-de-obra indígena fosse regulamentado. Além disso, os indígenas não poderiam permanecer indeterminadamente sob a guarda de particulares, nem poderiam sofrer maus tratos, afinal isso inviabilizaria o projeto pombalino de igualá-los aos demais vassalos. Porém, a regularização do uso do trabalho indígena não agradou àqueles que diretamente se beneficiavam dele. Esse conflito de interesses torna-se evidente nas fontes analisadas.

Por volta de 1780, numa carta sem lugar, data, nem destinatário, Bernardo José Pereira, ofereceu informações acerca dos indígenas guaranis no Continente. Segundo ele, desde que autoridades portuguesas haviam mandado formar o aldeamento de Rio Pardo e "distribuir-lhes ração de carne à custa da Real Fazenda para sua sustentação extraindo-se gados dos moradores da província", deu-se "ao mesmo tempo princípio ao extrair os gados para diária sustentação dos novos vassalos". O relato pretendia provar que o sustento e "os roubos dos índios guaranis e seus aliados vexados" era a razão da diminuição do rebanho vacum. A solução proposta era enviar os aldeados para a ilha de Santa Catarina, caso contrário "tudo vai dar em diminuição de vacas". (BNRJ - 7,3,48) Na visão estratégica de Bernardo José Pereira, que representava os interesses de estancieiros da região, a fome, a falta de providência dos indígenas e suas alianças com gaudérios iriam destruir as fazendas do Continente. Os gaudérios, "que na qualidade são meio espanhóis, outros índios bastardos de várias nações" e os guaranis destroçavam os campos de Viamão e Rio Pardo, sendo providencial enviá-los para outro lugar. O remetente arrazoava que certamente, os índios deveriam comer, mas tendo em vista o estoque supostamente insuficiente de gado, que eles pudessem se alimentar com "um excelente peixe das garoupas pescado com linhas e anzóis e redes de arrastar, em cujo trabalho da pescaria, podem entrar pequenos e grandes, homens e mulheres, e a turba de inválidos melhor e mais facilmente se sustentam com peixes mais do que com vacas que estão acabando-se". Tais iniciativas particulares de interagir com o governo central revelam que a mobilidade espacial dos indígenas deve ser analisada levando em conta as condições impostas por políticas indigenistas e as alternativas praticadas através de políticas indígenas. Sua movimentação pelas fronteiras platinas e a limitada ação de autoridades portuguesas e espanholas em contê-la, também estiveram relacionadas com extensas redes comerciais (MELO, 2011, 2018). ${ }^{9}$

Há informações importantes sobre a relação entre portugueses e os aldeados de Nossa Senhora dos Anjos nas cartas de Francisco José da Rocha. Rocha era um enviado especial do vice-rei marquês do Lavradio, incumbido da tarefa de dar conta de tudo que visse e ouvisse. Ao chegar no Continente, o projeto pombalino parecia ser realizável aos olhos de Rocha, que numa carta ao vice-rei avaliava que "pelo que diz respeito aos índios e índias, também se poder fazer tudo o que V. Ex a tem determinado" (ANRJ, Fundo Marquês do Lavradio, Microfilme 024-97, notação

\footnotetext{
8 Todos os trechos deste parágrafo são retirados deste documento.

${ }^{9}$ Pode-se observar os alcances das redes comerciais agenciadas por indígenas em outras regiões de fronteira no mesmo período, como em SOMMER, Barbara A. Cracking down on the Cunhamenas: Renegade Amazonian Traders under Pombaline Reform. Journal of Latin American Studies, v. 38, n. 4, p. 767-791, 2006.
} 
16.88, Rio Pardo, 30.08.1771), conquanto que se desse criação portuguesa às meninas, para que estas pudessem se casar com portugueses ${ }^{10}$. No ano seguinte, com uma opinião totalmente contrária à anterior, Rocha dava conta das condições adversas em que o Continente se encontrava: "Aqui, meu Senhor, há dois objetos principais neste Governo, que são as corridas de gado de Espanha, para melhor dizer furtos, e o governo dos Índios, que um e outro deixam bastantes lucros para quem os exercita e governa [...]". (ANRJ, Fundo Marquês do Lavradio, Microfilme 024-97, notação 16.76 a 16.78, Viamão, 27.01.1772).

Em 1772, o governo era exercido por Antônio Veiga de Andrade, cujos "defeitos" o enviado do marquês do Lavradio lamentava não ter descoberto anteriormente. Segundo Rocha, o governador havia feito uma sociedade com o líder de uma facção da elite local que se aproveitava da mão-de-obra indígena, e governava em benefício próprio e de seus "sequazes". Dificilmente as informações de Rocha eram infundadas, visto que um dos membros dessa facção da elite era o capitão Antônio Pinto Carneiro, comandante da aldeia de Nossa Senhora dos Anjos: "Mande V. Exa tomar uma conta exata a Pinto Carneiro dos couros e gados que tem consumido, depois que governa os índios, do consumo dos jornais dos mesmos índios e verá como o ponho: não foram atendidos e se acham na mesma miséria que os outros". (ANRJ, Fundo Marquês do Lavradio, Microfilme 024-97, notação 16.76 a 16.78, Viamão, 27.01.1772). Rocha mencionava a transferência de uma povoação de índios feita em acordo entre Veiga e o chefe da facção à qual ele se aliara. Como a permanência dos indígenas não representava benefício para os particulares, a transferência teria se dado em prejuízo dos mesmos e, portanto, em determinação contrária às instruções do Diretório, que previa que os índios fossem capazes de se sustentar com o próprio trabalho, e não que ficassem na miséria.

Assim como havia uma facção da elite que se beneficiava do uso do trabalho indígena e os queria por perto, havia um grupo que queria vê-los longe da região. Tratava-se de um grupo de fazendeiros de Viamão, que solicitava a transferência dos índios guarani para Santa Catarina. Através de uma carta, um autor anônimo informava a grande despesa dada aos estancieiros que forneciam ração de carne aos indígenas a mando da Fazenda Real. O representante dos estancieiros também acusava os indígenas de serem os responsáveis pelos furtos de gado na região. Essa correspondência não tem lugar, data, nem destinatário, mas provavelmente foi escrita no terceiro quartel do século XVIII e endereçada ao vice-rei. Segundo o remetente, o capitão da aldeia não tinha interesse em transferir os indígenas, pois utilizava sua mão-de-obra na propriedade que possuía próxima à aldeia dos Anjos.

Apesar dos conchavos com grupos da elite, Antônio da Veiga cumpriu uma importante determinação da política indigenista, ainda que tenha sido a pedido do vice-rei: a cooptação de lideranças. No início do ano de 1772, o Marquês do Lavradio solicitava ao governador que enviasse alguns indígenas à capital: "Poderá V. M. mandar quinze ou dezesseis, que venham vestidos e calçados até Santa Catarina para dali me serem remetidos na primeira ocasião, e o mais fica por minha conta: aqueles que forem filhos de caciques, ou dos que entre eles são mui distintos, destes fará separada menção, para que os possa conhecer [...]". O vice-rei fazia a solicitação como forma de remediar o "atraso dos índios" fazendo com que eles viessem "aprender os ofícios e artes a esta capital”. (ANRJ, Fundo Marquês do Lavradio, Microfilme 024-97, notação 2, p. 2.94/2.95, Rio de Janeiro, 11.02.1772). O governador Antônio da Veiga atendeu à solicitação do vice-rei e no mesmo mês baixou uma portaria sobre a determinação para o envio dos rapazes. Além de se tratar da ordem de um superior hierárquico, o envio de quinze ou dezesseis rapazes à capital do Rio de Janeiro provavelmente não inviabilizaria outros arranjos políticos entre o governador e parte da elite local. Havia muitas queixas contra os indígenas, principalmente da parte daqueles que não se beneficiavam das relações estabelecidas com os mesmos. Para que não houvesse "prejuízo dos moradores" do Continente e os interesses da Coroa fossem alcançados, era dever dos

${ }^{10}$ A política de incentivo aos casamentos mistos será tratada mais adiante. 
governadores fazer cumprir as determinações do Diretório.

José Marcelino, após retornar de uma temporada no Rio de Janeiro em meados de 1773 , retomava o controle da aldeia dos Anjos, dando seguimento a alguns dos principais preceitos da política de assimilação. Este governador criou seis companhias de ordenanças de Infantaria e Cavalaria, das quais os caciques foram capitães. O capitão-mor era Narciso da Costa Flores, o cacique Poti, que havia sido indicado pelos próprios indígenas: "Os caciques ficaram em capitães e os mais em subalternos, o Narciso da Costa Flores se $\mathrm{V}$. Exa o aprovar a voto dos principais deles em Capitão-Mor, e outro bom índio na mesma forma em Sargento Mayor, como V. Ex $x^{a}$ verá a lista de promoção". (BNL. Divisão de Reservados. Cód. 10854, carta do governador José Marcelino de Figueiredo ao vice-rei marquês do Lavradio. Porto Alegre, 29.07.1774) Com a criação das companhias e a nomeação dos indígenas para cargos de comando, José Marcelino promovia a assimilação por duas vias: primeiro, através da cooptação de lideranças; segundo, através da integração dos indígenas (tanto comandantes, quanto aldeados) em uma instituição de caráter militar, típica da sociedade colonial. Ao cooptar lideranças indígenas, as autoridades portuguesas se valiam do status que o principal ${ }^{11}$ gozava na aldeia. Sob a ótica indigenista, a influência que a liderança exercia sobre os aldeados era legítima e isso fazia com que a aliança estabelecida entre os líderes indígenas e o governo português pudesse ser melhor recebida e aceita no aldeamento. Por isso, a demonstração de respeito ao princípio de autodeterminação dos guaranis por parte do governador se mostrava bastante consciente dos resultados que tal iniciativa poderia trazer: "Ficaram muito satisfeitos, e estão a maior parte deles fazendo suas lavouras, pois lhes tenho encarecido muitas vezes o quanto útil e preciso se faz a agricultura neste Continente, como V. Ex ${ }^{a}$ tanto recomenda". (BNL. Divisão de Reservados. Cód. 10854, carta do governador José Marcelino de Figueiredo ao vice-rei marquês do Lavradio. Porto Alegre, 29.07.1774)

Em 1777, o governador fez um recolhimento para meninas com recursos "da sua grande estância que Ihe formei há anos para o comum" e, portanto, "sem despesa da Fazenda Real". Ele sugeria que os indígenas estavam em vias de se autossustentarem através dos rendimentos obtidos pelo próprio trabalho. A lida nas lavouras da aldeia promovia a integração do indígena por meio do trabalho, e também através do entendimento de que a atividade agrícola e o lucro oriundo dela, poderia lhes garantir certa autonomia. Além disso, através dos recolhimentos havia o entendimento de que ocorreria a integração dos indígenas através da eliminação de alguns dos seus traços culturais dos indígenas, como a língua e a religião: "Eu acabo agora de fazer segundo colégio, para recolher 50 meninas, pois a experiência me tem mostrado que só os 50 meninos recolhidos há um ano sabem falar português e a doutrina cristã, e muitos ler, e escrever e contar". (BNL. Divisão de Reservados. Cód. 10854, carta do governador José Marcelino de Figueiredo ao vice-rei marquês do Lavradio. Vila Nova dos Anjos, 22.06.1777)

Porém, em 1778, e já ao final do seu mandato, José Marcelino, quase em tom de desculpas, justificava a insuficiência de seus esforços. Apesar de ter "feito instruções e ordens que se acham registradas na dita vila para o bom governo dos índios", e também ter procurado meios para que fossem "úteis a si e ao Estado", o 'gentio' ainda não estava 'civilizado': "Poderá vencer a que aquelas gentes sejam como as nossas, e não poderá haver dúvida nisto se se conservarem as minhas disposições, e se $\mathrm{V}$. Ex ${ }^{a}$ for servido dar valor às minhas ordens para que outro governador ou comandante as não possa inovar, nem mudar". (BNL. Divisão de Reservados. Cód. 10854, carta do governador José Marcelino de Figueiredo ao vice-rei marquês do Lavradio. Porto Alegre, [corr.].05.1778. Os três últimos trechos foram extraídos desta mesma fonte) O próprio governador reconhecia que a aplicação das leis indigenistas foi submetida a diferentes interesses, que poderiam variar de governo para governo. Fica claro, portanto, que a aldeia dos Anjos teve a sua trajetória condicionada às negociações feitas entre os governos e as elites locais, combinadas às diretrizes da política pombalina, e aos interesses dos indígenas.

\footnotetext{
${ }^{11}$ Neste caso, o principal é a liderança indígena.
} 
Embora os interesses do governo, dos particulares e dos indígenas fossem na maioria das vezes conflitantes, pode-se dizer que houve tentativas no sentido de conciliá-las. Ainda que fosse burlando algumas regras do Diretório, ao beneficiar o líder de uma facção da elite em detrimento do 'progresso' dos indígenas, Veiga consentiu que uma povoação fosse transferida. Mesmo indo "contra a geral opinião de muitos" (BNL. Divisão de Reservados. Cód. 10854, carta do governador José Marcelino de Figueiredo ao vice-rei marquês do Lavradio. Vila Nova dos Anjos, 22.06.1777) e entrando em atrito com parte da elite local, José Marcelino fez cumprir algumas das diretrizes da política de assimilação dos indígenas. ${ }^{12}$ Não se pode dizer que ambos os governadores não levaram em conta seus próprios interesses. Para tanto, usaram as brechas encontradas na legislação, adequando-as ao que lhes parecia mais conveniente: "Apesar da evidente margem de manobra de que dispunham os governadores coloniais, sabe-se que estes funcionários deviam seguir as normativas e políticas metropolitanas, pelo menos em suas linhas gerais" (KÜHN, Fábio. 2007, p. 11). Nesse sentido, é importante pensar os instrumentos que viabilizaram a existência dessa margem de manobra. As próprias contradições presentes na legislação indigenista respaldavam a maleabilidade das quais os governadores se valeram ao aplicar a política assimilacionista.

\section{Aldeamentos no Continente sob a ótica indígena}

Há poucos registros escritos deixados pelos indígenas aldeados, mas mesmo nas fontes deixadas pelos colonizadores é possível encontrar elementos que permitem inferir a sua participação ativa no processo de organização e construção histórica do Continente. Ainda que a ação desses grupos tenha sido condicionada às pautas da sociedade colonial, foi possível estabelecer estratégias para sobreviver, adaptar-se e em certas ocasiões, exercer poder e ressignificá-lo conforme as necessidades criadas pelas experiências vividas. Então, a partir dessas reflexões, pode-se tomar os indígenas aldeados e as experiências vividas por eles como responsáveis pela formação de novas identidades (RIBEIRO, 2017). As novas formas de identificação surgidas em decorrência deste processo modificaram a alteridade daquela população indígena. Maria Regina Celestino, analisando a inserção de grupos indígenas em aldeias coloniais do Rio de Janeiro, considerou que "[...] uma outra referência de identificação, com certeza mais interessante para os índios em situação colonial, estava se formando: a de índio aldeado, identidade genérica e inicialmente dada pelos colonizadores, mas apropriada pelos índios que souberam utilizá-la para obter vantagens e benefícios que essa condição lhes proporcionava" (ALMEIDA, 2003, p. 259).

Sobre vantagens e benefícios da condição de aldeados, é interessante perceber que São Nicolau do Rio Pardo encontrava-se entre limites fronteiriços dos Impérios ibéricos e essa posição geográfica e política peculiar fez com que os indígenas tivessem suas chances de mobilidade espacial aumentadas. O tema sobre as fugas para e dos arredores de Rio Pardo está presente em vários documentos e já foi abordado em alguns trabalhos (MAEDER, 1992; GARCIA, 2009, p. 146148). Em 1759, o governador geral da Província do Rio da Prata e da cidade de Buenos Aires, Don Pedro de Cevallos, ordenou que se recolhessem informações sobre a retenção de desertores espanhóis, sobre a "sedução e extração de índios", e roubos e matanças de gado executadas pelos portugueses. O governador teve repetidas vezes notícias de que muitos dos índios e índias que haviam deixado os povos das missões orientais se encontravam nas imediações de Rio Pardo. Preocupado com a perda dos vassalos para o lado português e em saber quais as estratégias usadas para atrair e manter em seu território aqueles que haviam sido seus aliados, Don Pedro de Cevallos ordenou ao general-mor dos Reales Exércitos, Don Diego de Salas, que executasse

\footnotetext{
12 É importante detalhar que José Marcelino de Figueiredo era o nome fictício de Manuel Jorge Gomes de Sepúlveda, um militar português enviado ao Brasil em 1765, após ter cometido um delito que acabou por provocar a morte de um oficial britânico. Não parece descabido pensar que, a José Marcelino, seria mais prudente resguardar os interesses da Coroa portuguesa, ao invés de se aliar aos potentados locais.
} 
retenções e interrogatórios no quartel de São Borja. Os depoimentos fornecem informações sobre os índios que chegavam e saíam de Rio Pardo. É importante considerar que a posição estratégica de Rio Pardo e a existência do aldeamento em suas adjacências fizeram com que aquelas paragens fossem escolhidas como um dos destinos preferidos de desertores, índios, índias e 'chinas'. A maioria dos interrogados afirmou que, segundo o que haviam visto, os portugueses davam bom tratamento aos desertores espanhóis e, além disso, concediam também "libertad grande [...], pues ellos andavan como querian de rancho em rancho de china con el seguro de que no se les castigaria, siendo permitido vivir cada uno como queria". (AGS. [Valladolid]. Secretaria de Estado, Legajo 7405, documento 71: Quartel General de San Borxa. Año de 175913). Mesmo assim, havia desertores arrependidos e que queriam voltar para os exércitos espanhóis e não o faziam por receio dos castigos com os quais os portugueses os ameaçavam, incluindo os indígenas:

y que esto mismo sucede con maior rigor a los indios e indias que quieren, o intentan venirse a sus Pueblos, castigando a los que [ilegível] con las maiores prisiones y severidad, y que para evitar su fuga tienem [ilegível] todos los caminos con varias Guardias en distintos puertos, como el paso de San Lorenzo, y camino de Viamont, y añade que los mismos indios le han dicho que ellos se habian ido con los portugueses, fiados en las ofertas y promesas que les hicieron quando les aconselaron el que se fueran con ellos, pero que despues se habian desengañado, y visto de todo era embuste, y que se hallaban arrependidos e disgustados, y con grandes deseos de volverse a sus Pueblos, y que no lo hacian porque no davan lugar para ello, antes les castigavan com maior rigor si intentava alguno escaparse, como havia sucedido con muchos. (AGS. (Valladolid). Secretaria de Estado, Legajo 7405, documento 71: Quartel General de San Borxa. Año de 1759. Depoimento de Juan Forales, soldado blandengue da Companhia de Don Miguel Dominguez)

Pode-se perceber que há certa contradição no que se refere às ameaças portuguesas feitas aos desertores espanhóis e o bom tratamento que os mesmos portugueses lhes davam. É interessante notar, nesse sentido, que quando perguntados sobre as deserções, respondiam sobre os peões, os oficiais do exército, e também sobre os índios e índias que haviam encontrado, considerando a todos como desertores. Nem sempre é possível identificar se os índios eram tidos também como servidores do Exército, tanto pelos depoentes quanto pelos seus arguidores. Do mesmo modo, às vezes não é possível diferenciar as mulheres consideradas "chinas" das índias. Essas supostas confusões identitárias denotam não somente uma grande mestiçagem entre sujeitos históricos e práticas sociais, como também uma noção de mobilidade socioespacial que ultrapassa a noção de espaço territorial. Elas conduzem a pistas sobre possíveis maneiras de pensar e agir das pessoas envolvidas nessas situações. Como a ideia de pertencimento e de lealdade à Coroa portuguesa ou espanhola era entendida por esses agentes sociais? As noções sobre pertencimento e as diversas formas de usá-las estrategicamente pareciam se movimentar entre um lado e o outro dos complexos fronteiriços (BOCCARA, 2005, p. 42). Percebe-se, através de várias pistas presentes nesse documento, que de acordo com as situações com as quais se deparavam, os índios tinham escolhas a serem feitas. Assim, poderiam se identificar aos, como também ser identificados pelos funcionários do exército espanhol como índios guarani-missioneiros desejosos de retornar aos domínios do rei católico; e aos funcionários do exército português, como desertores espanhóis que, devido ao bom tratamento dado e a "liberdade" adquirida nos domínios do rei fidelíssimo, não desejavam retornar.

No começo da década de 1770, o vice-rei escrevia ao governador José Marcelino lamentando a ineficiência da religião e das leis promulgadas até então no processo de integração dos indígenas. O vice-rei arriscou alguns dos motivos pelos quais o aldeamento não obtinha sucesso. Segundo ele, talvez não estivesse havendo o cuidado necessário em se tomar as providências necessárias para a "corporação daquelas gentes". O marquês do Lavradio chamava

\footnotetext{
${ }^{13}$ Agradeço a Eduardo Neumann pela indicação e por ter proporcionado meu acesso a essa importante fonte histórica sobre a história de São Nicolau do Rio Pardo.
}

SÆCELUM - Revista de História [v. 26, n. 44]. João Pessoa, p. 388-404, jan./jun. 2021, ISSNe 2317-6725 
a atenção do governador para o fato de que o cuidado em relação aos índios deveria ser "um dos objetos mais principais de cuidado de quem governa este Estado", pois "daqueles estabelecimentos se poderá seguir não só a grandíssima fertilidade de sua Província que muito pode participar toda essa capitania, mas porque a mesma Província terá mais meios defensores para a sua conservação e poderemos defender as entradas nos domínios de El Rey meu Senhor, quando o orgulhoso ânimo dos nossos vizinhos ou quaisquer outros inimigos, nos queiram perturbar com as suas costumadas violências" (ANRJ, Fundo Marquês do Lavradio, Microfilme 024-97, notação 2, p. 2.54 a 2.56, Rio de Janeiro, 01.03.1771).

Os indígenas também pareciam ser conscientes do quanto eram importantes para "as utilidades" do Continente. À medida do possível, usaram o valor atribuído ao papel do indígena naquela sociedade, para obter vantagens e benefícios. Assim também, recusaram o que lhes pareceu causar um prejuízo maior. A integração dos indígenas dependia não somente da tomada de providências para que as leis promulgadas fossem cumpridas, como pensava o vice-rei. Dependia também do modo como os indígenas as receberiam. A relação entre portugueses e indígenas se deu através de negociações e do estabelecimento de alianças entre ambas. Estas passavam por vias que iam muito além da simples imposição de leis. Era preciso persuasão e convencimento, mas não da maneira tratada no Diretório, que pressupunha que somente o lado português pudesse convencer os indígenas e não o oposto. Pensar que a integração se daria na velocidade e nos moldes pretendidos pela Coroa, seria o mesmo que pensar que os indígenas aceitariam prontamente todas as adequações propostas pelo Diretório, sem vislumbrar nenhuma outra vantagem que não fosse a de ser 'súdito do rei'. As fontes analisadas oferecem elementos para pensar o quão inviável seria a integração dos indígenas se o Diretório fosse seguido à risca.

Francisco José da Rocha, ao prestar contas das suas atividades de espião ao marquês do Lavradio, deu-lhe algumas provas de que os indígenas eram conscientes de sua posição na sociedade colonial e sabiam negociar em benefício próprio. Ele foi à Aldeia dos Anjos, e através de um intérprete, disse aos índios "as honras que V. Ex ${ }^{a}$ Ihes fazia". No dia seguinte, recebeu uma visita do cacique Narciso da Costa Flores: "[...] veio o capitão-mor visitar-me e por uma fala pelo língua em que dizia fizesse certo a $\mathrm{V}$. Ex ${ }^{\mathrm{a}}$ de um agradecimento, que todos o estimavam por ser $\mathrm{o}$ primeiro que os honrava depois do Senhor Conde de Bobadela, a quem eram obrigados pelos tirar das suas terras, e tratar com tanto mimo, que eles estavam prontos a servir El-Rey e fazer tudo o que Exa quiser" (ANRJ, Fundo Marquês do Lavradio, Microfilme 024-97, notação 16.5 a 16.12, Rio Pardo, 22.10.1771).

O cacique Poti se referia às negociações feitas com o conde de Bobadela, em virtude do traslado de parte da população guarani-missioneira da região das missões para Rio Pardo. Ele mostrava gratidão e disposição em retribuir a 'dívida', demonstrando ser um útil vassalo do rei e um aliado das autoridades portuguesas. Narciso justificava sua posição de capitão-mor das companhias de ordenanças da Vila Nova dos Anjos, mostrando-se um intermediário nas negociações feitas entre indígenas e portugueses. Ao mesmo tempo, o cacique Poti representava a comunidade indígena enquanto uma liderança que havia sido escolhida pelos próprios índios, na busca por vantagens que a aliança feita em outrora com as autoridades portuguesas poderia lhes render. Ao ser uma liderança indígena, Narciso resguardava um traço cultural guarani, e que, portanto, fazia parte da identidade indígena: o costume de eleger seus representantes. Por outro lado, novos componentes eram agregados à identidade dos aldeados: a condição de súditos do rei e aliados das autoridades portuguesas. Ademais, o cacique Poti passou a receber 320 réis diários através de uma portaria baixada pelo governador José Marcelino (AHRS, Os Índios d'Aldeia dos Anjos Gravataí, século XVIII. Porto Alegre, EST, 1990, p. 19). Fica claro, portanto, que a cooptação de lideranças era uma política que poderia ser vantajosa tanto para o lado indígena, quanto para o lado português. O mesmo se poder dizer a respeito da realização de casamentos mistos.

A política assimilacionista não apenas incentivou, mas enfatizou a necessidade de 
realização destes consórcios, ora propondo aos cônjuges preferência na ocupação de cargos administrativos (no caso masculino) e dotes (no caso feminino), ora oferecendo aos filhos desta união, a mesma chance ou possibilidade de inserção social. Essa determinação era válida tanto para portugueses que viessem a se casar com índias, quanto para portuguesas que viessem a se casar com índios, embora o primeiro caso fosse mais comum. Isso demonstra o quão significativo era o interesse do governo português nesses casamentos.

Rocha recebeu, além da visita do cacique Poti, um convite para ir assistir aos festejos que faziam em louvor ao vice-rei. Indo à Aldeia, Rocha presenciou o desprezo com que os portugueses tratavam os indígenas. Com a finalidade de promover a política de assimilação, ele tomou algumas providências práticas: "[...] e um de muitos que mostravam este desprezo prendi, e outro que deu em um índio por lhe pedir dois vinténs castiguei na presença deles, e à vista de todos pus o Capitãomor à minha mesa; fez isto tal impressão de brio, nos índios e nos portugueses, que já temos cinco casados com índias, entrando neste número três soldados [...]" (ANRJ, Fundo Marquês do Lavradio, Microfilme 024-97, notação 16.5 a 16.12, Rio Pardo, 22.10.1771). Pelo visto, nem sempre os dotes e a preferência na ocupação de cargos públicos eram suficientes para que os casamentos mistos se realizassem. Com a atitude de Rocha os portugueses notaram a importância dada pelas autoridades lusas aos indígenas. Do mesmo modo, os indígenas perceberam o quanto eram valorizados pelo enviado do vice-rei e fizeram valer essa condição em benefício próprio. Provavelmente, o status social e político de aliados do representante de uma ilustre autoridade portuguesa, era mais vantajoso para os indígenas do que o recebimento de um dote, ou a ocupação de um cargo público. Pode-se dizer que a iniciativa de Narciso Flores ao visitar Francisco da Rocha surtiu efeito positivo para ambos os lados. Rocha foi padrinho desses casamentos e fez com que alguns oficiais e soldados acompanhassem a cerimônia.

Em 1776, o governador José Marcelino escreveu exultante ao vice-rei, exclusivamente para participá-lo das proezas dos índios da vila dos Anjos. Alguns soldados da cavalaria de voluntários de São Paulo haviam desertado, dos quais uma parte foi rapidamente presa. O restante havia se embrenhado no mato depois de ferir alguns soldados. José Marcelino encarregou a companhia Ligeira da vila nova dos Índios de apanhá-los e trazê-los de volta "para serem processados estes celerados": "eles deram tão boa conta desta incumbência, que apesar das maiores dificuldades e trabalhos dentro nos matos, os apanharam todos treze, e os faço entregar ao seu comandante" (ANRJ, Fundo Marquês do Lavradio, Microfilme 024-97, notação 16.5 a 16.12, Rio Pardo, 22.10.1771).

É possível pensar que os indígenas haviam dominado um importante código do mundo colonial: o do valor dos serviços prestados à Coroa portuguesa. Dificilmente a companhia Ligeira da vila nova dos Anjos ${ }^{14}$ tinha como único intuito agradar ao governador, como de fato conseguiu. Os indígenas usaram as suas habilidades para realizar com êxito uma tarefa delegada a eles pelo governador. O fato de terem apanhado todos os treze desertores, quando outra diligência provavelmente não teria conseguido, demonstra que os indígenas usaram sua "qualidade de índios" para obter reconhecimento de uma importante autoridade. Isso denota que os indígenas eram cientes do quanto a prestação desse tipo de serviço era importante naquele contexto de conquista de territórios, onde as guerras pela definição de fronteiras eram constantes. ${ }^{15} \mathrm{~A}$ posição social de peão indígena do Exército ou de soldado indígena lhes garantiu um lugar de destaque: "Esta diligência feita por Índios me satisfez muito, e creio que as deserções pararão, vendo que não é certo escaparem como tinham para si, que em se metendo no mato ninguém os apanhava" (BNL. Divisão de Reservados. Cód. 10854, carta do governador José Marcelino de Figueiredo ao vice-rei

\footnotetext{
${ }^{14}$ Após a implementação da legislação pombalina, a aldeia dos Anjos se tornou uma vila portuguesa, conforme especificado no parágrafo 2 do Diretório.

${ }^{15}$ A Cavalaria de Voluntários de São Paulo, da qual os desertores faziam parte, veio para auxiliar o Continente na situação de guerra.
} 
marquês do Lavradio. Porto Alegre, novembro de 1776 [não consta o dia]).

A despeito das demonstrações de que os indígenas se integravam à sociedade lusobrasileira, José Marcelino, ao final de seu governo, considerou que a aldeia dos Anjos não havia alcançado bons resultados. Segundo ele, os indígenas "trabalhavam para todos e para a Fazenda Real, e não percebiam do seu salário mais do que uma ração de carne, e no fim ordinariamente lhe davam com um pau [...]". O governador mencionava várias medidas assimilacionistas que obtiveram êxito, como a construção de uma igreja pelos índios, a formação de recolhimentos para meninos e meninas sem que houvesse despesa da Fazenda Real. No entanto, ponderava que teria conseguido resultados melhores, caso não fosse: "[...] a guerra há três anos, e ser preciso muitos centos de Índios ocupados em peões do Exército, e gastadores, e na Marinha, com cujo número tiveram as lavouras quebra, e os mais índios e índias pés para fugirem para o Rio Grande [...]" (BNL. Divisão de Reservados. Cód. 10854, carta do governador José Marcelino de Figueiredo ao vice-rei marquês do Lavradio. Porto Alegre, novembro de 1776).

De acordo com José Marcelino a Vila dos Anjos contava com mais de três mil índios, mas muitos andavam dispersos, "e não haverá 20 que compreendam nossa língua portuguesa, suposto falam muitas palavras". Ao que parece, os indígenas se integravam à sociedade colonial pelos caminhos que lhes pareciam mais oportunos. No contexto da guerra, alguns indígenas perceberam que talvez as condições de inserção social seriam melhores em Rio Grande do que na vila dos Anjos. Os índios poderiam prestar bons serviços ao Exército português e obter proveitosos reconhecimentos em função disso. Não é descartada, ainda, a possibilidade de aliança com os espanhóis. Entre outros, essa possível aliança era um dos fortes motivos para a política de bom tratamento aos indígenas por parte do governo português. Certamente, as índias também vislumbravam melhores condições de vida ao fugirem para Rio Grande. José Marcelino, estando ciente das fugas, pediu "muitas vezes" os índios e índias ao 'Sr. General'; este respondia que lá não havia os índios necessários e nenhuma índia. Isso demonstra que os indígenas, em certo momento, tiveram suas utilidades reconhecidas pelo general, que não quis mandá-los de volta ao aldeamento. Algumas índias só retornaram à vila dos Anjos após terem ocasionado "desordens na tropa" (BNL. Divisão de Reservados. Cód. 10854, carta do governador José Marcelino de Figueiredo ao vice-rei marquês do Lavradio. Porto Alegre, novembro de 1776).

As reiteradas medidas para livrar a Fazenda Real da despesa com indígenas, podem ter sido umas das razões pelas quais alguns deles preferissem fugir do aldeamento. Nos dois últimos anos de seu governo, José Marcelino baixou portarias bastante taxativas a esse respeito. Em 1779, ordenou a suspensão da ração de carne que os indígenas recebiam da Fazenda Real: "mandandoa somente continuar aos enfermos da capital, aos presos, aos meninos e meninas dos colégios que formei para a sua educação, e aos cegos e aleijados e aos que por muito velhos não podem trabalhar, e a cada mulher parida nos primeiros quinze dias [...]" (AHRS, Livro de Registro Geral da Fazenda Real. Códice F 1244, p. 157/157v. Registro de uma portaria do Sr. Brigadei-ro Governador José Marcelino para se suspender a ração de carne às famílias guaranis. Porto Alegre, 2 de janeiro de 1779). Em outra portaria, no ano de 1780, José Marcelino mandava suspender além da ração de carne, a assistência hospitalar, a não ser em casos de "extrema necessidade e por ordem minha" (AHRS, Livro de Registro Geral da Fazenda Real. Códice F 1244, p. 173v. Registro de uma portaria do Sr. Brigadeiro Governador José Marcelino para se suspender a ração de carne e assim a assistência do hospital que se costumava fazer a alguns pobres. Porto Alegre, 3 de janeiro de 1780). De acordo com o governador, ele havia conseguido "pelo método do trabalho e agricultura" que os indígenas fossem capazes de se sustentar: "agora vejo se pode inteiramente fazer cessar a despesa da mesma Fazenda Real com os mesmos índios, pois que o seu comum pode sustentar os que foram até aqui excetuados" (AHRS, Livro de Registro Geral da Fazenda Real. Códice F 1244, p. 
$175 / 175 v) .^{16}$

Cabe lembrar que o mesmo governador, em uma carta ao vice-rei havia reconhecido que os indígenas trabalhavam para a Fazenda Real e para todos e não recebiam por isso mais do que uma ração de carne e maus-tratos. Agora, fazia cessar o único pagamento que os indígenas que permaneceram aldeados tinham pela prestação dos seus serviços: a ração de carne. As informações de José Marcelino são no mínimo incompatíveis e remetem à complexidade daquele momento histórico. Ao final de seu mandato, os rapazes indígenas que foram enviados à capital para aprender "ofícios e arte" pelo governador Antônio da Veiga, ainda não haviam regressado. Oito anos depois, o governador pedia ao vice-rei que mandasse um órgão e "alguns músicos dos rapazes Índios que lá foram aprender, para tocar dito órgão, pois cá ainda não tenho quem o faça" (AHRS, Livro de Registro Geral da Fazenda Real. Códice F 1244, p. 175/175v) ${ }^{17}$. Caso os rapazes indígenas tivessem conseguido se inserir socialmente na capital, poderia se pensar que o primeiro passo dado nesse sentido, teria sido o fato de serem filhos de lideranças indígenas.

É possível, portanto, inferir que os indígenas também foram responsáveis pelo declínio do aldeamento $^{18}$, que se extinguiria oficialmente na década de 1860 , à medida que buscaram alternativas para se integrar àquela sociedade em formação. Nesse sentido, foram partícipes do processo de construção social e cultural tanto quanto os portugueses. $O$ fato de os indígenas reconhecerem possibilidades de sobrevivência ou a perspectiva de uma situação que lhes fosse mais favorável, não significava que estivessem dispostos a deixar de ser índios. A política pombalina previa a integração dos indígenas através da incorporação de elementos da cultura portuguesa e da eliminação de traços culturais indígenas. Porém, é evidente que houve situações em que, justamente, a condição de índios aldeados fez com que os indígenas se inserissem. A integração dos indígenas não significava que estivessem dispostos a deixar de lado sua identidade, eliminando todos os seus traços culturais para absorver o modo de vida luso-brasileiro. A dispersão populacional, por exemplo, era uma constante no comportamento indígena, apesar das determinações em sentido contrário, o que denota uma forma de insubordinação ao confinamento territorial que se pretendia impor. Uma grande parte dos indígenas aldeados se encontrava dispersa. Do mesmo modo, um número reduzido falava o português, resguardando um traço fundamental de sua identidade cultural: a língua guarani. A disparidade quantitativa entre esses dados denota que preservavam, de acordo com as possibilidades, alguns traços culturais e políticos que os mantinham com uma identidade indígena. Através da incorporação de outros elementos à sua cultura política, os indígenas conseguiram fazer com que essas novas identidades sobrevivessem.

\section{Um olhar sobre outros olhares}

A aplicação e a recepção da legislação indigenista e as relações dela resultantes, parecem ter acontecido fazendo jus à complexidade inerente ao processo, e de acordo com as especificidades de situações distintas como diferenças de gênero, faixa etária e posição hierárquica. Assim, no caso dos casamentos mistos, as índias encontravam maior possibilidade de inserção social. No caso dos recolhimentos e colégios, as crianças eram privilegiadas no acesso à educação, podendo encontrar nessa distinção uma possibilidade de integração. No caso da ocupação de cargos públicos, os índios eram beneficiados. De acordo com Gerald Sider, "when a dominated people just simply continues to socially live within and against the dominant society, this continually forces both the larger society and the people themselves to change their ways, their methods of

\footnotetext{
${ }^{16}$ Registro de uma portaria do Sr. Brigadeiro Governador José Marcelino em que manda suspender todas as rações às famílias guaranis da Vila nova dos Anjos. Porto Alegre, 3 de janeiro de 1780.

${ }_{17}$ Registro de uma portaria do Sr. Brigadeiro Governador José Marcelino em que manda suspender todas as rações às famílias guaranis da Vila nova dos Anjos. Porto Alegre, 3 de janeiro de 1780.

${ }^{18}$ Refiro-me aqui ao declínio da estrutura do aldeamento, pois conforme foi exposto, os indígenas e suas identidades não desapareceram após a extinção oficial daquele espaço em 1861/1862.
} 
coping and claiming, their understanding of the possible and the impossible. Their changes are often small, but can be crucial ${ }^{19 "}$ (SIDER, 1994, p. 118). Logo, não faz sentido pensar que os portugueses manteriam sua matriz cultural simplesmente eliminando elementos da cultura indígena, sem incorporá-los. No processo de construção de identidades há trocas culturais que reacomodam novas realidades sociais. É preciso problematizar explicações tradicionais e interrelacionar as diferentes histórias. Segundo Boccara (BOCCARA, 2005, p. 42),

\begin{abstract}
"los trabajos recientes en términos de mestizaje, middle ground, etnogénesis y etnificación permiten evitar caer en el culturalismo antropológico, esa forma duradera de esencialismo [...]. Los agentes sociales, a pesar de la fuerza o del peso de los procesos de socialización, adaptan sus comportamientos a situaciones novedosas a fortiori cuando se encuentran confrontados a momentos de crisis (social, demográfica, ideológica) o a transformaciones profundas en la larga duración"20.
\end{abstract}

Assim, houve estratégias e tomadas de posição distintas para promover a integração social, algumas delas incluindo violência, tanto por parte dos indígenas aldeados em São Nicolau do Rio Pardo e Nossa Senhora dos Anjos, quanto por parte dos portugueses. É certo que as possibilidades de escolha não eram equânimes, e que, muitas vezes, os ganhos não eram os esperados. Mas as opções feitas, algumas das quais em situações limite, foram importantes nos processos de apropriação cultural e, por conseguinte, nos processos de reelaboração de identidades. Existiram várias posições, das quais os portugueses puderam olhar a relação com os indígenas; ora como mera mão-de-obra, ora como aliados, ora como intermediários. Assim também, os indígenas ocuparam posições das quais puderam ver as relações com os portugueses sob diferentes ângulos. Houve um processo constituído não apenas por diretrizes oriundas do Diretório dos Índios e ditadas pela Coroa, mas também pelos interesses de colonos da região e dos próprios guaranis estabelecidos.

As relações sociais que se estabeleceram tinham como intuito acabar com a completa separação entre brancos e indígenas, porém as mudanças delas decorrentes transformaram de maneiras ímpares a alteridade da população indígena e consequentemente sua incorporação à sociedade colonial. À luz de novos olhares, suas ações sociais e as responsabilidades pelas construções de suas identidades podem ser historicamente (re)conhecidas.

\title{
Abreviaturas
}

AHRGS - Arquivo Histórico do Rio Grande do Sul

ANRJ - Arquivo Nacional do Rio de Janeiro

BNL - Biblioteca Nacional de Lisboa

IHGB - Instituto Histórico e Geográfico Brasileiro

\section{Documentos manuscritos}

Arquivo Histórico do Rio Grande do Sul

\footnotetext{
${ }^{19}$ Quando um povo dominado apenas continua a viver socialmente com e contra a sociedade dominante, isto continuamente força ambos, a sociedade envolvente e os próprios povos a mudar seus caminhos, seus métodos de assimilar e reclamar, seus entendimentos do possível e impossível. [TA], livre tradução da autora.

20"Os trabalhos recentes em termos de mestiçagem, middle ground, etnogênese e etnificação permitem evitar cair no culturalismo antropológico, esta forma duradouro de essencialismo [...]. Os agentes sociais, apesar da força ou do peso dos processos de socialização, adaptam seus comportamentos a situações cheias de novidades a fortiori quando se veem confrontados a momentos de crise (social, demográfica, ideológica) ou a transformações profundas na larga duração" [TA].
} 
Códice 1244, fl. 157-157v; fl. 171v-172; fl. 173; fl.175-175v; fl. 185.

Arquivo Nacional do Rio de Janeiro

Códice 104 v.6, fl.174v-175.

Biblioteca Nacional de Lisboa

Divisão de Reservados, PSS, caixa 3.

Biblioteca Nacional do Rio de Janeiro. 7, 3, 48.

\section{Instrumento de pesquisa}

Anais do Arquivo Histórico do Rio Grande do Sul. Arquivo Histórico do Rio Grande do Sul, Porto Alegre, 1995. Volume 11.

\section{Documentos Microfilmados}

Microfilme 024-97, Notação 2 - Correspondência do Vice-Rei com governadores - Cartas do Marquês do Lavradio para José Marcelino de Figueiredo, p. 2.32-2.35; 2.52-2.53; 2.54-2.56.

\section{Documentos impressos}

AHRS, Os Índios d’Aldeia dos Anjos: Gravataí, século XVIII. Porto Alegre, EST, 1990.

REVISTA TRIMENSAL DO INSTITUTO HISTÓRICO GEOGRÁPHICO E ETHNOGRÁPHICO BRASILEIRO; tomo XXXV, Companhia Tipográfica do Brasil, Rio de Janeiro, 1872. Carta de Francisco Xavier de Mendonça Furtado para o vice-rei Conde da Cunha. Lisboa, 18.03.1767.

Diretório que se deve observar nas povoações dos índios do Pará e do Maranhão enquanto sua majestade não mandar o contrário. Apud, ALMEIDA, Rita Heloísa de. O Diretório dos Índios. Um projeto de civilização no Brasil do século XVIII. Brasília: Editora UnB, apêndice.

\section{Referências}

ALMEIDA, Maria Regina Celestino de. Metamorfoses indígenas: identidade e cultura nas aldeias coloniais do Rio de Janeiro. Rio de Janeiro: Arquivo Nacional, 2003.

ALMEIDA, Rita Heloísa de. O Diretório dos Índios. Um projeto de civilização no Brasil do século XVIII. Brasília: Editora UnB, 1997.

BOCCARA, Guillaume. Memoria Americana. Cuadernos de Etnohistoria. Génesis y estructura de los complejos fronterizos euro-indígenas, repensando los márgenes americanos a partir (y más allá) de la obra de Nathan Wachtel. Buenos Aires, n. 13, 2005.

FLORES, Moacyr. A transmigração dos guaranis para a Aldeia de Nossa Senhora dos Anjos. In: Anais do II Simpósio Estadual sobre cultura Gravataiense, Gravataí: do êxodo à composição étnica. Gravataí: Secretaria de Educação e Cultura, 1990.

GARCIA, Elisa Frühauf. As diversas formas de ser do índio: políticas indígenas e políticas indigenistas no extremo sul da América. Niterói, PPG-História/UFF, Tese de Doutorado, 2007.

KÜHN, Fábio. O "Governo dos Índios": a Aldeia dos Anjos durante a administração de José Marcelino de Figueiredo (1769-1780). Em texto da comunicação oral ao III Encontro de Escravidão e Liberdade no Brasil Meridional. Florianópolis, 2007.

LANGER, Protásio Paulo. Os Guarani-Missioneiros e o Colonialismo Luso no Brasil Meridional, 
Projetos Civilizatórios e Faces da Identidade Étnica (1750-1798). Porto Alegre: Martins Livreiro, 2005.

MELO, Karina Moreira Ribeiro da Silva e. A Aldeia de São Nicolau do Rio Pardo no Oitocentos: histórias vividas por índios guaranis (séculos XVIII-XIX). 2011. 167 p. Dissertação (Mestrado em História). Porto Alegre: Universidade Federal do Rio Grande do Sul.

MELO, Karina Moreira Ribeiro da Silva e. A execução do tratado de Santo Ildefonso e as atuações indígenas na fronteira platina. Revista Brasileira De História \& Amp; Ciências Sociais, v. 10 (19), p. 169-187, 2018.

PERRONE-MOISÉS, Beatriz. Índios Livres e Índios Escravos: Os princípios da legislação indigenista do período colonial (séculos XVI a XVIII). In: CUNHA, Manuela Carneiro da (org.). História dos Índios do Brasil. São Paulo: Companhia das Letras, 1992, p. 115-132.

RIBEIRO, Max Roberto Pereira. A terra natural desta nação guarani: identidade, memória e reprodução social indígena no Vale do Jacuí (1750-1801). 2017. Tese (Doutorado em História). São Leopoldo: Universidade do Vale dos Sinos.

SAMPAIO, Patrícia Maria Melo. Espelhos Partidos: etnia, legislação e desigualdade na Colônia. Manaus: Editora da Universidade Federal do Amazonas, 2011.

SIDER, Gerald. Identity as History, Ethnohistory, Ethnogenesis and Ethnocide in the Southeastern United States. Identities Global Studies in Culture and Power. New Hampshire, vol. 1, 1994.

\section{Nota de autoria}

Karina Moreira Ribeiro da Silva e Melo é doutora em História Social pela Universidade Estadual de Campinas (Unicamp). Mestra, licenciada e bacharela em História pela Universidade Federal do Rio Grande do Sul. Atua principalmente nos temas: história indígena, Brasil colonial e imperial, fronteiras. É professora adjunta na Universidade Estadual de Pernambuco/UPE e é professora colaboradora do Mestrado Profissional em Culturas Africanas, da Diáspora e dos Povos Indígenas (PROCADI) E-mail: karina.melo@upe.br.

\section{Como citar esse artigo de acordo com as normas da revista}

MELO, Karina Moreira Ribeiro da Silva e Melo. Políticas indígenas e indigenistas no Continente de São Pedro na segunda metade do século XVIII. Sæculum - Revista de História, v. 26, n. 44, p. 388404, 2021.

\section{Contribuição de autoria}

Não se aplica.

\section{Financiamento}

CNPq.

\section{Consentimento de uso de imagem}

Não se aplica.

\section{Aprovação de comitê de ética em pesquisa}

Não se aplica.

\section{Licença de uso}

Este artigo está licenciado sob a Licença Creative Commons CC-BY. Com essa licença você pode compartilhar, adaptar, criar para qualquer fim, desde que atribua a autoria da obra.

\section{Histórico}

Recebido em 31/03/2021. 
Modificações solicitadas em 08/06/2021.

Aprovado em 24/06/2021. 